\title{
The Hole in Holistic Patient Care
}

\section{Connie Drury, Jennifer Hunter}

School of Nursing and Health Sciences, University of Missouri-Kansas City, Kansas City, MO, USA

Email: cdrury@sehcollege.edu

How to cite this paper: Drury, C. and Hunter, J. (2016) The Hole in Holistic Patient Care. Open Journal of Nursing, 6, 776792.

http://dx.doi.org/10.4236/ojn.2016.69078

Received: August 1, 2016

Accepted: September 26, 2016

Published: September 29, 2016

Copyright $\odot 2016$ by authors and Scientific Research Publishing Inc. This work is licensed under the Creative Commons Attribution International License (CC BY 4.0).

http://creativecommons.org/licenses/by/4.0/

\begin{abstract}
Throughout its history, the nursing profession has claimed to provide holistic patient care, which is defined as bio-psycho-socio-spiritual care. Today, however, many nurses do not feel comfortable with the "spiritual" element of care and are uncertain about their professional role in the assessment and delivery of spiritual care. Discomfort and avoidance of attending to the spiritual needs of human beings creates " $\mathrm{a}$ hole" in holistic patient care. Contributing factors to the "hole in holistic patient care" include: 1) blurring of boundaries in the language and definitions of "spirituality" and "religion", 2) insufficient attention to definitions of spirituality and spiritual distress; 3 ) confusion and role conflict with professional identity among disciplines related to responsibility for spiritual care; 4) insufficient education and skill development for nurses and other healthcare professionals in the assessment, intervention and appropriate referral of patients experiencing spiritual distress. The purpose of this article is to explore the history of holistic nursing as it pertains to the human dimension of spirituality and conclude with practice models for spiritual assessment and spiritual care that can "fill" the hole in holistic nursing care.
\end{abstract}

\section{Keywords}

Spirituality, Holistic, Nursing, Spiritual Distress

\section{Introduction}

Life threatening illness and related suffering are arguably situations in which holistic care is the most important. Holism, a century old concept, refers to healing the whole person-body, mind and spirit-rather than solely focusing on the physical suffering and treatment of a disease or condition. Holistic healing is the creation of a harmonious healing balance among the body, mind and spirit of each patient to achieve health for the entire being [1] [2]. Holistic care thus includes care for the whole person, includeing physical, psychosocial, emotional and spiritual care. Avoidance of spiritual care, 
that is, attending to the spiritual needs of human beings by any health care professional, creates "a hole" in holistic patient care.

Provision of spiritual care is significant, as research has shown not only that spiritual health is related to better overall health outcomes but also that healthcare consumers believe that spiritual needs should be addressed by healthcare providers [3]. Better health outcomes that can be promoted with spiritual care include disease prevention and recovery, sense of overall wellbeing, and enhanced ability to cope with illness and adjust to stress-related life events [4]-[7]. Spiritual and religious interventions have been shown to decrease suicide rates, substance abuse, divorce and depression in some populations [8] [9]. Research findings indicate that patients expect nurses to help them explore the meaning of suffering, and arrange for privacy for participation in spiritual and religious customs [7] [10]. It will be argued that nurses have the unique opportunity to enrich the hospital experience, to improve the quality of life for patients suffering from serious to terminal disease, and to improve patient's satisfaction by attending to the spiritual needs of their patients.

Nursing, as a profession, has historically claimed to provide holistic care, yet, research indicates that many nurses do not feel comfortable or are not adequately trained to address the "spiritual care" dimension of their patients [11]-[14]. Holistic nursing is defined by the American Holistic Nurses Association as "all nursing that has healing the whole person as its goal" [15]. The following sections will explore the history of holistic nursing as it pertains to the dimension of spirituality, barriers and misconceptions related to spiritual care, and end with a review of existing practice models for spiritual care and spiritual assessment tools that could promote the filling of the "hole" in holistic care.

\section{Holistic Nursing: Historical Perspectives on Spirituality in Healthcare}

Humans have inherently cared for the sick thus, the history of nursing worldwide is quite substantial [16]. A brief history of nursing is fundamental for understanding the progression of spiritual care in addressing the holistic health needs associated with human suffering. Holistic origins, the attrition of spirituality from nursing with the advancement of the scientific era, to the re-emergency of spirituality in healthcare will be reviewed.

\subsection{Holistic Origins}

Dating back 20,000 years, Shamanism is the oldest approach to healing and still exists today [17]. Practically every native community used some type of Shamanism [16]. Shamanism assumes that the combination of body, mind and spirit is a single inseparable entity rather than a consolidation of parts [16]. Shamans are individuals who the tribe believes possess special gifts for understanding and controlling the spiritual realm of others. Incantations, spells, drums, chanting, medicinal plants and rituals are used in the treatment of pain, sickness and suffering. The source of illness within Shamanism is attributed to the loss of "personal power" that makes an individual vulnerable to sick- 
ness [17].

In 500 B. C. an ancient Greek physician, Hippocrates, advised those who nursed the sick be attentive to the spiritual wellbeing of their patients and "to do no harm" [18]. From 700 B.C. to 300 A.D. ancient Greeks erected healing temples called Asclepions (named after the Asclepius, the Greek god of healing) which were sites of healing for the body, mind, and spirit [17]. Ancient Greek health practices offered in the temples included art, drama, music, prayers to the gods, rest, massage, herbs and basic surgeries, with some interventions performed by priest healers [17] [19].

In the early years of Christianity, widows were the caretakers of the poor and afflicted. The term "widow" was a title that referred to pious older women who devoted their time caring for the less fortunate, elderly, and those stricken with illness [17]. Later the widows formed religious orders that performed acts of charity and works of mercy. Corporal works of mercy meant nurturing the spirit through tending to the physical ailments of the body. Treatment often involved exorcism, as illness was attributed to possession by evil spirits.

Christianity reigned throughout the Middle Age era with religious orders establishing hospitals to facilitate the care of sick [16]. Medieval hospitals had high mortality rates due to the lack of hygiene and curative treatments. Nursing care was limited to comfort measures such as providing shelter, nourishment, personal care, and prayer. Thus, the primary focus in caring for the sick was nursing the soul.

\subsection{Holistic Care Wanes with Scientific Revolution}

The era of holistic healing began to fade with the onset of the Scientific Revolution [17] [19]. Rene Descartes, a $17^{\text {th }}$ century philosopher expressed the perception that the body and mind are each a separate entity that can best be understood through separation, rationalization, and reasoning [17]. This Cartesian dualism ushered in the scientific approach to viewing and treating illness from a purely physiological perspective. As specializations evolved in medical science, Western medicine distanced itself even further from the healing of the human spirit.

Florence Nightingale was the first nurse trained within a scientific curriculum who is recognized for practicing holistic care to patients by combining spirituality and science [17]-[19]. Nightingale believed that healing is a dynamic process of recovering from an affliction or disease, mending that which is damaged and, restoring and transforming the individual's body, mind, and spirit [20]. Nightingale personified her principle that spirituality is both "intrinsic to humans and compatible with science" [21].

Most early to mid- $20^{\text {th }}$ century nursing schools in the United States maintained some aspect of spirituality through their affiliation with major religious denominations [18]. Yet, as nursing curricula focused more on the scientific approach to nursing care, the characteristics of care, compassion, and empathy became less obvious [17]. In the later $20^{\text {th }}$ century, university and college-affiliated programs established baccalaureate, masters, and doctoral programs in nursing. Great advances were being made in medical technology and knowledge in the biological and behavioral sciences was flourishing. 
Along with these advancements, the focus of nursing curricula shifted from preparation for a spiritual vocation to preparation for a skilled, scientific profession. It can be said that the paradigm of nursing shifted from an art to a science [18].

\subsection{Re-Emergence of Spirituality within Healthcare}

In the past few decades, the role of spirituality in health care has regained the attention of health care providers, nursing organizations, regulating agencies, researchers and consumers During the 1970's and 1980's the importance of holistic health care was re-ignited, as was spiritual health and spiritual care of the sick. In 1981, the American Holistic Nurses Association was established in by Charlotte McGuire in response to a substantial nursing shortage, as nurses were leaving acute care settings to pursue opportunities that would allow them to refocus on healing the "whole" rather than merely curing disease [15] [22]. Holistic healthcare was defined by Cathie Guzzetta in 1988 as, "a sensitive balance between art and science, analytic and intuitive skills, and the ability and knowledge to choose from a variety of treatment modalities to promote balance and interconnectedness of body, mind, and spirit" [23]. Within this definition and others, spiritual needs are viewed as equally important to the physiologic and psychosocial needs in the provision of nursing care [18].

In 2001, the American Nurses Association developed a Code of Ethics for Nurses, declaring that nurses are to implement measures that promote the physical, psychological and spiritual wellbeing of their patients. Joint Commission on the Accreditation of Health Care Organizations has since mandated that accredited health care institutions "accommodate" both religious and spiritual care needs of their patients [23]-[25]. Research has strengthened the push for spiritual care by revealing not only that spiritual health is related to better overall health outcomes but also that the majority of healthcare consumers believe that spiritual needs should be addressed by healthcare providers [3]. Findings have reliably established a direct relationship between spiritual health and medical outcomes including disease prevention and recovery, sense of overall wellbeing, and enhanced ability to cope with illness [4] [6] [7]. A meta-analysis of 49 studies encompassing over 13,000 subjects linked positive religious coping to an individual's ability to adjust to stress-related life events, while negative religious coping was associated with anxiety, depression, and distress [4]. In another study, supportive spiritual care in terminally ill patients was associated with improved quality of life, patient satisfaction, increased hospice referrals, decline in the use of extensive medical treatments, and decreased medical expenses [5]. A study on the coping abilities of patients with human immunodeficiency virus (HIV), revealed that intense spiritual events allowed them to better cope with pain, anxiety, despair, and impending death [4]. Multiple studies have associated spiritual and religious interventions in the mentally ill with decreased readmission rates, suicides, substance abuse, divorce, depression, criminal behavior, and improved overall mental health [8] [9].

In studies of patient perceptions, patients have consistently professed their desire for physicians and nurses to "consider" religious and spiritual needs and preferences in the 
delivery of patient care [5] [26]-[28]. Research findings indicate that patients expect nurses to help them explore the meaning of suffering, and arrange for privacy to allow for participation in prayer, spiritual customs and rituals [7] [10]. It is argued that nurses have the unique opportunity to enrich the hospital experience, improve the quality of life for patients suffering from serious or terminal disease and improve patient satisfaction by tending to spiritual needs of their patients. Resolution of spiritual uncertainty ushers in the spiritual peace necessary to achieve a heightened quality of life [7] [26] [28]-[31]. All of these effects are well documented in a large body of research on spirituality in patients diagnosed with a serious, advanced or terminal illness [5] [7] [27] [32]-[35]. Thus, evidence supports regulatory and organizational actions, discussed above, which have formally re-established the need for the role of the nurse to be a healer of the integral tapestry of the human, body, mind and spirit. If one thread of this integral tapestry begins to unravel, the whole tapestry is at risk for disintegrating into a meaningless pile of thread.

\section{Barriers to Spiritual Care}

Regardless of research evidence and organizational and accreditation mandates, attention to spirituality often falls short in the current health care system [36]. Reasons for this include: a) a blurring of religion and spirituality boundaries; b) insufficient attention to definitions of spirituality and spiritual distress; c) role conflict with professional identity and role confusion among disciplines related to responsibility for spiritual care; and d) insufficient education and skill development for nurses and other healthcare professionals related to assessment, intervention, and appropriate referral for patients experiencing spiritual distress [11] [23] [36] [37]. Although these barriers affect various healthcare providers however, in the following section, we will predominantly address how they apply to the nursing profession. As seen, nursing as a profession has historically claimed to provide holistic care, the definition of which includes spiritual care, yet research indicates that many nurses do not feel comfortable or adequately trained to address the "spiritual" dimension of their patients [11]-[14].

\subsection{Blurring of Religion and Spirituality}

One challenge of defining spirituality is that the boundaries between spirituality and religion are often poorly defined or nonexistent. This erroneous blurring of the two is often seen in the language of both research and practice related to spiritual care wherein it is implied that religion and spirituality are synonymous terms [12] [38]. Spirituality naturally exists within each human being while one's religion or religious affiliation is a personal choice [12]. Religion can be defined as an organizational system created by an individual or group that accept the same beliefs, values, sacred text, rituals and divine being [12] [38] [39].

Spirituality is a broader concept that may be expressed through an individual's religious beliefs, practices and rituals but, religion is not necessary for spirituality to exist [12] [36] [40]-[43]. The word "spirituality" originates from the "Latin spiritus, meaning 
breath, and relates to the Greek pneuma or breath, which refers to the vital spirit or soul" [12]. Dossey and Keegan [12] describe spirituality as:

The essence of our being. It permeates our living in relationships and infuses our unfolding awareness of who we are, our purpose in being, and our inner resources. Spirituality is active and expressive. It shapes- and is shaped by-our life journey. Spirituality informs the ways we live and experience life, the ways we encounter mystery, and the ways we relate to all aspects of life. Inherent in the human condition, spirituality is expressed and experienced through living our connectedness with the Sacred Source, the self, others, and nature.

According to Vachon [43], “...spirituality could be defined as 'a search for meaning and purpose in life' or as, 'a feeling to have found a meaning and purpose in life and death"'. Pesut [44] and others have described spirituality as the core of our being and existence: "To be human is to be spiritual".

\subsection{Insufficient Attention to Definitions of Spirituality and Distress}

Most researchers agree that developing a simple standardized definition of spirituality to fit all individuals in all situations is an ambiguous, if not, impossible task. However, many human experiences are subjective and difficult to standardize, yet our study of these subjective human experiences proceeds. Similarly, it is possible to identify a working definition of spirituality for research and practice by drawing on the essential aspects of various definitions. These include:

- a search for and/or sense of meaning and purpose in life,

- connectedness to something beyond the self, which can include a higher power, loved ones, nature, art or music, and

- a source of inner strength to transcend the stressors of existence and suffering and optimally, to maintain physical, psychosocial and spiritual wellness.

These essential aspects within definitions of spirituality form the logical basis for the nursing diagnosis of "Spiritual Distress" as described by the North American Nursing Diagnosis Association (NANDA) [45] [46]. NANDA's current definition of spiritual distress is, "A state of suffering related to the impaired ability to experience meaning in life through connections with self, others, the world or a superior being" [47]. Symptoms that may indicate spiritual distress per NANDA include: anxiety, crying, fear, fatigue, insomnia, anger, guilt, isolation, hopelessness and isolation. A stronger awareness and focus on these essentials-the search for life meaning, a need for connectedness, and inner strength to transcend suffering-as well as the related NANDA definition of spiritual distress would: a) decrease the blur between religion and spirituality; b) enable relevant spiritual assessment, patient education, interventions and referrals related to spiritual health; and c) help clarify role confusion among disciplines.

\subsection{Conflict with Nursing "Professionalism"}

Issues around spirituality for nursing are largely related to the strong, though erroneous, equating of spirituality with religion, and religion being something they most often do not see as a part of their professional scope of practice, given its now strong scientif- 
ic basis. As society and health care have become increasingly secularized, nurses have grown more anxious and unsure about balancing their own beliefs and professional nursing roles when providing spiritual care [48]. Secularization and intolerance to religious beliefs has made nurses apprehensive in addressing patients' spirituality for fear of being accused of proselytizing personal beliefs and values on their patients [12] [48]. Those nurses who aspire to include spiritual care in their nursing practice, however, are aware that providing such care to their patients can be accomplished without imposing personal and religious beliefs or needing expertise in any particular religion [12] [48]. As a profession, nurses must become knowledgeable, proficient and secure in providing spiritual care, per accurate definition of spirituality, in order to truly be holistic caregivers.

\subsection{Role Confusion among Disciplines}

Much of the literature identifies that one of the key challenges in addressing the spiritual tasks of patients is the inability to clearly identify the provider of spiritual care [2] [7] [40]. According to Brunjes [49], physical pain is treated by the patient's physician, mental anguish by the psychiatrist, and social pain attended to by a social worker or other social support system, but the referral agent for spiritual pain remains a mystery. The answer to this riddle is not such a mystery for those who attest that the chaplain is the spiritual expert in treating the soul, much like the physician is the expert for the physical body [23] [25] [50]. Healthcare providers tend to agree that referral to the hospital or palliative care chaplain is logical for addressing the spiritual and religious needs of patients [2] [7] [51].

Pastoral care professionals are trained to provide spiritual care and guidance to diverse religious denominations, those who do not have a particular religious affiliation, and those who claim to have no faith whatsoever [23] [50]. In reality, however, the ratio of chaplains to patients is quite small and chaplaincy programs have not gained the momentum to train more chaplains, as jobs in healthcare are scarce and salaries are low [45] [50]. Thus, the more realistic question may not be "Who is the responsible health care professional to provide spiritual care to patients" but rather "What is the role of each healthcare provider on the multi-disciplinary team in meeting the spiritual needs of patients?" Many feel that all healthcare professionals should claim at least a share of the responsibility for addressing the spiritual needs of patients since the establishment of trust between any healthcare provider and patient, at any given moment, can open the door for honest communication concerning spiritual feelings that could lead to the resolution of spiritual distress [23] [52]. Who provides spiritual care is not nearly as important as assuring that each healthcare professional has the resources, guidance and interdisciplinary support to meet the spiritual needs of any patient or family who trusts them enough to share spiritual concerns [49].

\subsection{Lack of Education and Skill Development for Spiritual Care}

The lack of education and direction within nursing curricula hinders the ability to in- 
corporate spiritual care into practice for patients experiencing spiritual distress [2] [5] [7] [29] [53]. Improving the competence of nurses in defining spirituality beyond religion, and in identifying and addressing symptoms of spiritual distress would enhance patient outcomes of finding life meaning and purpose, connectedness, inner strength and a state of spiritual peace-all of which can be severely disrupted by life threatening illness and impending death [12]. Through guidance and mentoring, nurses and other health care professionals can be empowered to provide spiritual care, to advance holistic practice and to better meet the needs of patients and their families [7]. Nursing faculty, who may also feel inadequacies related to spiritual care, can be assured that creating such guidance for students does not rest solely on their shoulders, but, that numerous models of spiritual care and tools for spiritual assessment already exist.

\section{Spiritual Care Models, Assessment Tools and Basics of Intervention}

Awareness of existing resources for spiritual care and a level of proficiency in assessing spirituality is necessary. However, it is not meant to intrude or intervene in religious areas, but rather to explore the patient's individual sources of meaning, purpose and strength in life, sense of hope, connectedness, beliefs and values, and, most importantly, how illness has impacted these essential life structures [42] [54]. The erroneous use of vocabulary associating spirituality solely with religion can be avoided by continually drawing on holistic definitions of spirituality and the nursing diagnosis of spiritual distress.

In Cadge and Bandini's [36] review of the evolution of spiritual assessment tools, authors identify that over 40 such tools have been developed since the 1970s, predominantly by chaplains, nurses, physicians and social workers. Tool creation has occurred far more often in disciplinary silos than through interdisciplinary collaboration. Cadge and Bandini [36] assert that the evolution of spiritual assessment tools, and the involvement of the disciplines creating them, reflects larger societal shifts in the U.S. across the years. The various societal shifts and health care responses are also reflected in newer models for spiritual care, some which are interdisciplinary. Such societal influences have included the development of clinical pastoral education (CPE) that integrated psychology and theology, Medicare reimbursement based on diagnosis related groups (DRGs), the history of holistic care reflected in nursing, the hospice and palliative care movement, Joint Commission standards for health care organizations, and ongoing chaplaincy debates between approaches of unstructured spiritual presence versus a more structured approach to spiritual diagnosis and care planning. The latter is similar in many ways to nursing's path to professionalism, inclusive of the "nursing process" structure, theory and research to support an evidence based practice. Territoriality, often spawned by the disciplinary survival need to document their contribution to patient care, has also influenced claims of who is best qualified to diagnose spiritual problems and implement spiritual care. In response to both increased interdisciplinary collaboration, as well as territoriality, spiritual assessment has also undergone a "triage" 
process of sorts, being divided into screening processes for immediate crises, followed by more in depth spiritual histories. The result is a diversity of tools ranging from the two-question variety to full narrative, life history assessments.

As nurses review various spiritual care models to find an approach most relevant to their practice-they can compare the language, structure and functioning of disciplines within the models to see what might fit best within their given health care structure and philosophy of care. Likewise, when reviewing assessment tools to find resources most relevant to individual practice settings, perhaps the most important aspects to compare in the structure, language and questions posed in these tools are: 1) their focus, whether religion-limited or broader life meaning, purpose and connectedness; and 2) the length and time required to complete the tool; 3 ) where the tool should be integrated into practice, i.e. admission screening or a more in-depth spiritual assessment or spiritual history; and 4) how the tool can be used in practice i.e. using it as a formal tool or adaptation to an informal, conversational approach to spiritual assessment. Although not all inclusive, several spiritual care models are briefly described here, followed by several existing spiritual assessment tools.

\subsection{Practice Models for Spiritual Assessment and Spiritual Care}

\subsubsection{The Spiritual Care Implementation Model}

According to Christine Puchalski, the creator of the Spiritual Care Implementation Model [25], spiritual care is necessary in any patient-centered health care system. The model is described as a relational model, and illustrates a process of how the patient and interdisciplinary healthcare providers should work together in discovering, communicating, collaborating, managing, evaluating and follow-up to verify the effectiveness of the plan and modify the treatment plan as needed. The Spiritual Care Implementation Model has two "sub-models," one being a specific model for inpatient and a second, different model, for outpatient clinical settings. The Spiritual Care Implementation Model is also described as a "generalist-specialist model of care" in that boardcertified chaplains are considered the spiritual care specialist of the team, but all members of the team should be generalists in their ability to be "first responders" to spiritual needs-that is, to identify, assess and respond initially and potentially to make a referral to the chaplain specialist [25].

In the Inpatient Model, the implementation of spiritual care begins with a brief spiritual screening to promptly determine if the patient is experiencing spiritual distress [25]. A more in-depth spiritual assessment is included within the psychosocial history portion of the clinical record to aid in identifying significant information regarding the patient's essential needs, hopes, and available resources that can help health care providers determine whether the patient's spiritual status will enhance or complicate the overall medical care. If concerns arise regarding the patient's spiritual health, a referral brings a board-certified chaplain who will complete a comprehensive spiritual assessment which allows the patient to tell their story. The board-certified chaplain will develop a spiritual treatment plan which will be communicated to the entire treatment 
team, and will extend to discharge planning, bereavement care, and procedures that enable the interdisciplinary team follow-up contact with family and loved ones after the patient's death.

\subsubsection{The Principle Components Model}

The Principle Components Model is the result of grounded theory study by Wilfred McSherry [52], based on interviews with members of multiple health care disciplines. The model emphasizes six components, which include: individuality, inclusivity, inter-intra-disciplinary, integrated, innate and institution. Individuality refers to the numerous characteristics that shape the uniqueness of an individual's spirituality, such as culture, religious affiliation life events, social positioning, experiences and traditions. Inclusivity refers to consideration of patient, health care providers and family caregivers in assessing understanding, uncertainties and specific languages of spirituality that are meaningful, versus those that could alienate patients from seeking spiritual guidance. Inter-intra-disciplinary indicates that no single discipline is exclusively responsible for the provision of spiritual care, but that collaboration is imperative. Lastly integrated is the component that motivates the healthcare team to avoid fragmenting holistic care by separating the spiritual from the physical or psychosocial aspects of each patient in the delivery of healthcare. Implementation of the Principle Components Model could aid in finding a language of spirituality that is meaningful and applicable for the assessment and treatment of patients experiencing spiritual distress, developing practice guidelines for the delivery of spiritual care to diverse populations, structuring services involved in the provision of spiritual care and advancing the knowledge and skills necessary for understanding, assessing and providing for the spiritual needs of patients and their loved ones.

\subsubsection{The Four Domains Model of Spiritual Health and Wellbeing}

The Four Domains Model of Spiritual Health and Wellbeing, developed by John Fisher, ascribes that the spiritual state of each individual determines the general wellbeing of all other human dimensions [55]. In this model the domains of spirituality are identified as "personal, communal, environmental and transcendental" [55]. Every domain consists of two aspects, knowledge and inspiration. Spiritual health is attained by cultivating positive connections within each domain and is enhanced by integrating additional domains, a process termed "progressive synergism." Personal growth within a domain not only strengthens the domain, but also overall spiritual health. The four domains model can be utilized as a foundation for development and refinement of theory and spiritual assessment tools.

\subsubsection{The $7 \times 7$ Model}

The $7 \times 7$ Model was designed and published in the late 1980s and early 1990s by an interdisciplinary team headed by chaplain researcher George Fitchett, to provide a framework that views spirituality as an inseparable entity from the body and mind yet does not presume what spirituality entails [56]. The model identifies seven holistic dimensions including: medical, psychological, family systems, ethnic and culture, societal 
and spiritual, as they intersect with seven attributes of spirituality including "beliefs and meaning, vocation and consequences, experience and emotion, courage and growth, ritual and practice, community, authority and guidance." The aspects of the $7 \times 7$ model are described in detail without the inclusion of a formal set of questions allowing the healthcare professional flexibility in the amount of time allotted for the assessment and consideration of the patient's clinical circumstances.

\subsection{Spiritual Assessment Tools}

According to Cadge and Bandini [36], currently there are over 40 spiritual assessment tools identified in United States literature that have been created by various healthcare professionals including physicians, chaplains, nurses and social workers. Few of these tools were created through multidisciplinary collaboration or intended for interdisciplinary use; most were created within disciplinary silos. Lack of cooperation between disciplines in assessing spirituality has presented challenges in the communication among healthcare professionals about patients' spirituality and planning spiritual care as well as, wide-spread variation in the care provided. Language used in various tools ranges from traditional focus on faith and religion to a broader more existential approach. It is important to examine the content of assessment questions, therefore, to ensure a match with nursing philosophy and diagnoses. Just a few of these tools are briefly described here.

\subsubsection{The Spiritual Profile Assessment (SPA)}

An exception to the lack of cross disciplinary work occurring in the 1980s, physician Elisabeth McSherry collaborated with chaplains to develop the first physician's spiritual assessment tool, the Spiritual Profile Assessment (SPA). The SPA included three questionnaires-the Professional Health Inventory, Religiosity Index, and Ultimate Values Test [36] [57]. The purpose of the comprehensive Spiritual Profile Assessment was to assist chaplains in planning and documenting spiritual care for individual patients.

\subsubsection{The JAREL Spiritual Wellbeing Tool}

The JAREL tool [58] is an example of spiritual assessment tools designed for a specific population. This tool was designed by nurses to evaluate faith, life and satisfaction of patients over the age of 65 years, meant to build on clients' strengths and help foster personal growth.

\subsubsection{The FICA Tool}

The FICA tool was published 1996 by physician Christine Puchalski to help physicians and other health care professionals address spiritual issues [31] [36]. The FICA acronym prompts questions related to F: Faith and belief, I: Importance, C: Community, and A: Address. "Address" refers to questions about how their spirituality can be addressed within their health care.

\subsubsection{The HOPE Tool}

In 2001, Gowri Anandarajah and Ellen Hight introduced the HOPE tool at least in part 
in response to Joint Commission requirements [36] [59]. The initial intent of the HOPE tool was to aid medical students and physicians in posing questions regarding patients' sources of "H: hope, meaning, comfort, strength, peace, love and connection; O: organized religion; P: personal spirituality and practices; E: effects on medical care and end-of-life issues [59].

\subsubsection{Screening for Spiritual Distress}

Many nursing assessments done in hospitals upon admission of a patient have a "spiritual assessment tool" which is boiled down to one or two questions. Questions, such as "what is your religion (if any)?” and “would you like to see a chaplain?" seem intended to pass the buck versus actually learn anything about the patient. Keeping with the need to be efficient by limiting the assessment to a few questions, yet seeking to increase the effectiveness of those questions, Blanchard, Dunlap and Fitchard [45], developed and initiated a quality improvement project aimed at improving the collaboration between nurses and chaplains in assessing and referral of oncology patients who may experience spiritual distress during hospitalization. The primary goal was to train nurses to be more proficient at identifying patients who are at risk for experiencing spiritual distress. A simple algorithm commences with the nurse's statement, "Our team is committed to the whole person. Do you have a belief, spiritual or otherwise, that is important to you?" Based upon the patient's response, the nurse inquires, "Is that helping you now?" or "Was there a time that you did?" [45]. Through this algorithm, two types of spiritual distress are distinguished. In the first type, the patient reports having specific established beliefs, but these beliefs are not a source of support at this time. The second type, the patient had specific established beliefs in the past but does not adhere to those beliefs currently. In both types of responses, the nurse initiates a chaplain referral. By placing these two questions on the nursing assessment, not only was the risk for spiritual distress identified early in hospitalization, but it allowed for the initiation of spiritual dialogue between the patient and nurse.

\subsection{Unstructured Assessment and Intervention}

Even if a formal assessment tool is not available, spiritual assessment and the simple intervention of listening can be accomplished by asking open-ended questions that ease the patient into a candid discussion about how illness has impacted their ability to enjoy the things that are meaningful to them and how it has impacted their sense of purpose in life. Though very often religion will often be involved in that meaning and purpose, the nurse need not worry about asking direct questions about religion.

Communication skills are vital for building a patient relationships founded on trust, identifying spiritual distress, and implementing interventions that can ease the patient's suffering soul [52]. Especially important is the art of cultivating trust through active listening and presence so as to help the patient feel secure enough to be open about spiritual concerns and needs [13] [52] [60]. As an attentive listener, the healthcare provider must be able to involve the whole self in listening to the patient without intolerance or pondering on how to respond. While being attentive to the patient's posture, expres- 
sions and other "nonverbal cues" that might indicate spiritual struggle or suffering. In the business of the healthcare environment, it is easy to miss signals that a patient simply does not want to be alone, and presence may be the single, most vital spiritual intervention a healthcare provider can implement.

Much like active listening, presence requires the body, mind, and spirit of the nurse to be exclusively present for the patient. Resonating the Zen Buddhist philosophy, an American physician suffering from terminal illness, wrote a leaflet entitled, "Don't just do something, stand there" [60]. There comes a time when patients simply want to feel the security and companionship of human presence [33] [43]. Through the gentle caring presence of the healthcare, empathy for the patient's pain and suffering is personified allowing the patient to feel valued and respected [13] [60] [61]. Each of these skills has a twofold purpose, spiritual assessment and spiritual intervention.

Other interventions may be more specific to religious aspects, such as supporting religious rituals, practices, and prayer. When asked about spiritual interventions, nurses and patients often allude to prayer [7] [32] [33] [62]. The varieties of prayer differ from person to person and may be founded upon religious affiliation and culture [12]. According to Dossey \& Keegan [12], "prayer flows from the yearnings of the soul that rise from a place too deep for words and moves to a space beyond words." A patient's need for prayer may be satisfied through song, sacred text, meditation, speaking in tongues, silence, reciting traditional prayers, dance, or experiencing nature through simply being in the moment. Healthcare providers can facilitate prayer or contemplation by simply providing privacy and a quiet, peaceful atmosphere for patients and family.

Sawatzky and Pesut [19], defined spiritual care as "an intuitive, interpersonal, altruistic and integrative expression that is contingent on the nurse's awareness of the transcendent dimension of life, but that reflects the patient's reality". This definition of spiritual care is practical because it highlights that spiritual care should commence with the patient's current reality rather than meet some standardized guidelines or nurse expectations [60]. In the clinical setting, spiritual care is rarely based upon some preexisting, written, plan of care rather, it is often the nurse acting in response to a sudden unexpected patient dilemma [60].

\section{Summary}

Although U.S. health care claims to provide holistic care, research shows that many nurses, as well as other professionals, do not feel comfortable or are not adequately trained to address the "spiritual" dimension of their patients. This dimension has been both separated and integrated into health care through history from ancient times to scientific eras. Spiritual care has most recently received increasing attention, and is currently mandated by various health care organizations. Despite this, and despite the existence of numerous spiritual assessment tools and spiritual care models, barriers continue to exist, such as blurred boundaries between spirituality and religion, related role conflict over providing care deemed "religious", role confusion over bearing responsibility for spiritual care, and inadequate training for health care professions re- 
lated to spiritual assessment and care. In recent research, there are conflicts revealed between existing definitions of spirituality and understanding of the meaning of spirituality by health care providers, as well as differences in understanding between health care providers and patients. A return to basic spirituality definitions-focusing on life meaning and purpose, connectedness (to others, a higher power, nature), and inner strength to transcend stress and suffering-as well as interdisciplinary communication to promote common language and goals related to spiritual care can do much to provide increased clarity of purpose, role, and processes of spiritual care giving.

\section{References}

[1] Cooper, K.L., Chang, E., Sheehan, A. and Johnson, A. (2013) The Impact of Spiritual Care Education upon Preparing Undergraduate Nursing Students to Provide Spiritual Care. Nurse Education Today, 33, 1057-1061. http://dx.doi.org/10.1016/j.nedt.2012.04.005

[2] Narayanasamy, A. and Owens, J. (2001) A Critical Incident Study of Nurses' Responses to the Spiritual Needs of their Patients. Journal of Advanced Nursing, 33, 446-455. http://dx.doi.org/10.1046/j.1365-2648.2001.01690.x

[3] Puchalski, C.M. (2007) Spirituality and the Care of Patients at the End-of-life. OMEGA, 56, 33-46.

[4] Ano, G.G. and Vasconcelles, E.B. (2005) Religious Coping and Psychological Adjustment to Stress: A Meta-Analysis. Jounral of Clinical Psychology, 61, 461-480.

http://dx.doi.org/10.1002/jclp.20049

[5] Balboni, M.J., Sullivan, A., Amobi, A., Phelps, A.C., Gorman, D.P., Zollfrank, A., Balboni, T.A., et al. (2013) Why Is Spiritual Care Infrequent at the End of Life? Journal of Clinical Oncology, 31, 461-467. http://dx.doi.org/10.1200/JCO.2012.44.6443

[6] Coyle, J. (2002) Spirituality and Health: Towards a Framework for Exploring the Relationship between Spirituality and Health. Journal of Advanced Nursing, 37, 589-597. http://dx.doi.org/10.1046/j.1365-2648.2002.02133.x

[7] Gallison, B.S., Xu, Y., Jurgens, C.Y. and Boyle, S.M. (2013) Acute Care Nurses' Spiritual Care Practices. Journal of Holistic Nursing, 31, 95-103. http://dx.doi.org/10.1177/0898010112464121

[8] Chidarkikire, S. (2012) Spirituality: The Neglected Dimension of Holistic Mental Health. Advances in Mental Health, 10, 298-302. http://dx.doi.org/10.5172/jamh.2012.10.3.298

[9] Gleason, J.J. (2004) Pastoral Research: Past, Present, and Future. The Journal of Pastoral Care and Counseling, 58, 295-306. http://dx.doi.org/10.1177/154230500405800402

[10] Ross, L. (2006) Spiritual Care in Nursing: An Overview of the Research to Date. Journal of Clinical Nursing, 15, 852-862. http://dx.doi.org/10.1111/j.1365-2702.2006.01617.x

[11] Carr, T.J. (2010) Facing Existential Realities: Exploring Barriers and Challenges to Spiritual Nursing Care. Qualitative Health Research, 20, 1379-1392. http://dx.doi.org/10.1177/1049732310372377

[12] +Learning, Burlington.

[13] Puchalski, C.M., Lunsford, B., Harris, M.H. and Miller, T. (2006) Interdisciplinary Spiritual Care for Seriously Ill and Dying Patients: A Collaborative Model. The Cancer Journal, 12, 398-416. http://dx.doi.org/10.1097/00130404-200609000-00009

[14] Wallace, M., Grossman, S., Campbell, S., Robert, T., Lange, J. and Shea, J. (2009) Integration of End-of-life Care Content in Nurse Curricula: Student Knowledge and Perceptions. 
Journal of Professional Nursing, 25, 50-56. http://dx.doi.org/10.1016/j.profnurs.2008.08.003

[15] American Holistic Nurses Association (2007) Holistic Nursing: Scope and Standards of Practice. Nursebooks.org: The Publishing Program of ANA, Silver Spring.

[16] Barnum, B.S. (2006) From Traditional to New Age: Spirituality in Nursing. 2nd Edition, Springer Publishing Company, New York.

[17] Dossey, B.M., Keegan, L., Guzzetta, C.E. and Kolkmeier, L.G. (1988) Holistic Nursing: A Handbook for Practice. Aspen Publishers, Rockville.

[18] O’Brien, M.E. (2011) Spirituality in Nursing: Standing on Holy Ground. 4th Edition, Jones \& Bartlett Learning, Sudbury.

[19] Sawatzky, R. and Pesut, B. (2005) Attributes of Spiritual Care in Nursing Practice. Journal of Holistic Nursing, 23, 19-33. http://dx.doi.org/10.1177/0898010104272010

[20] O’Brien, K.M. and Gates, M.F. (2007) Teaching Holistic Nursing: The Legacy of Nightingale. Nursing Clinic of North America, 42, 309-333. http://dx.doi.org/10.1016/j.cnur.2007.03.007

[21] Maher, P. (2006) Reclaiming Spirituality in Nursing. In: Andrist, L., Nicholas, P. and Wolf, K., Eds., A History of Nursing Ideas, Jones and Bartlett, Sudbury, 417-420.

[22] Keegan, L. (1988) The History and Future of Healing. In: Dossey, B., Keegan, L., Guzzetta, K. and Kolkmeier, L., Holistic Nursing: A Handbook for Practice, Aspen, Gaithersburg, 5676.

[23] Handzo, G. and Koenig, H.G. (2004) Spiritual Care: Whose Job Is It Anyway? Southern Medical Journal, 97, 1242-1244. http://dx.doi.org/10.1097/01.SMJ.0000146490.49723.AE

[24] Joint Commission of the Accreditation of Healthcare Organizations (2004) http://www.jointcommission.org/

[25] Puchalski, C., Ferrell, B., Virani, R., Otis-Green, S., Baird, P., Bull, J., Sulmasy, D., et al. (2009) Improving the Quality of Spiritual Care as a Dimension of Palliative Care: The Report of the Consensus Conference. Journal of Palliative Medicine, 12, 885-904. http://dx.doi.org/10.1089/jpm.2009.0142

[26] Astrow, A.B., Wexler, A., Texeira, K., He, M.K. and Sulmasy, D.P. (2007) Is Failure to Meet Spiritual Needs Associated with Cancer Patients' Perceptions of Quality of Care and Their Satisfaction with Care? Journal of Clinical Oncology, 25, 5753-5757. http://dx.doi.org/10.1200/JCO.2007.12.4362

[27] Ramondetta, L.M., Sun, C., Surbone, A., Olver, I., Konishi, T., Baider, L. and Johnson, J. (2013) Surprising Results Regarding MASCC Members' Beliefs about Spiritual Care. Support Care Cancer, 21, 2991-2998. http://dx.doi.org/10.1007/s00520-013-1863-y

[28] Williams, J.A., Meltzer, D., Arora, V., Chung, G. and Curlin, F.A. (2011) Attention to Inpatients' Religious and Spiritual Concerns: Predictors and Association with Patient Satisfaction. Journal of General Internal Medicine, 26, 1265-1271. http://dx.doi.org/10.1007/s11606-011-1781-y

[29] Balboni, T.A., Paulk, M.E., Balboni, M.J., Phelps, A.C., Loggers, E.T., Wright, A. A., Prigerson, H.G., et al. (2010) Provision of Spiritual Care to Patients with Advanced Cancer: Associations with Medical Care and Quality of Life Near Death. Journal of Clinical Oncology, 28, 445-452. http://dx.doi.org/10.1200/JCO.2009.24.8005

[30] Lichter, D.A. (2013) Studies Show Spiritual Care Linked to Better Health Outcomes. Health Progress, 94, 62-66. www.chausa.org

[31] Puchalski, C. and Romer, A.L. (2000) Taking a Spiritual History Allows Clinicians to Understand Patients More Fully. Journal of Palliative Care, 3, 129-137. 
http://dx.doi.org/10.1089/jpm.2000.3.129

[32] Dobratz, M.C. (2012) “All My Saints Are within Me”: Expressions of End-of-Life Spirituality. Palliative and Supportive Care, 11, 1-8.

[33] Hermann, C.P. (2001) Spiritual Needs of Dying Patients: A Qualitative Study. Oncology Nursing Forum, 28, 67-72.

[34] Miller, W.R. and Thoresen, C.E. (2003) Spirituality, Religion, and Health: An Emerging Research Field. American Psychologist, 58, 24-35. http://dx.doi.org/10.1037/0003-066X.58.1.24

[35] Ross, L. and Austin, J. (2013) Spiritual Needs and Spiritual Support Preferences of People with End-Stage Heart Failure and Their Carers: Implications for Nurse Managers. Journal of Nursing Management, 23, 87-95. http://dx.doi.org/10.1111/jonm.12087

[36] Cadge, W. and Bandini, J. (2015) The Evolution of Spiritual Assessment Tools in Healthcare. Society, 52, 430-437. http://dx.doi.org/10.1007/s12115-015-9926-y

[37] Flannelly, K.J., Galek, K., Bucchino, J., Handzo, G.F. and Tannenbaum, H.P. (2005) Department Directors' Perceptions of the Roles and Functions of Hospital Chaplains: A National Survey. Hospital Topics. Research and Perspectives in Healthcare, 83, 19-27. http://dx.doi.org/10.3200/HTPS.83.4.19-28

[38] Nardi, D. and Rooda, L. (2011) Spirituality-Based Nursing Practice by Nursing Students: An Exploratory Study. Journal of Professional Nursing, 27, 255-263. http://dx.doi.org/10.1016/j.profnurs.2011.03.006

[39] Sinclair, S., Pereira, J. and Raffin, S. (2006) A Thematic Review of the Spirituality Literature within Palliative Care. Journal of Palliative Medicine, 9, 464-479. http://dx.doi.org/10.1089/jpm.2006.9.464

[40] Chochinov, H.M. and Cann, B.J. (2005) Interventions to Enhance the Spiritual Aspects of Dying. Journal of Palliative Medicine, 8, S103-S115. http://dx.doi.org/10.1089/jpm.2005.8.s-103

[41] Delgado, C. (2005) A Discussion of the Concept of Spirituality. Nursing Science Quarterly, 18, 157-162. http://dx.doi.org/10.1177/0894318405274828

[42] Johnson, L.S. (2003) Facilitating Spiritual Meaning-Making for the Individual with a Diagnosis of a Terminal Illness. Counseling and Values, 47, 230-240. http://dx.doi.org/10.1002/j.2161-007X.2003.tb00269.x

[43] Vachon, M., Fillion, L. and Achille, M. (2009) A Conceptual Analysis of Spirituality at the End of Life. Journal of Palliative Medicine, 12, 53-59. http://dx.doi.org/10.1089/jpm.2008.0189

[44] Pesut, B. (2008) A Conversation on Diverse Perspectives of Spirituality in Nursing Literature. Nursing Philosophy, 9, 98-109. http://dx.doi.org/10.1111/j.1466-769X.2008.00341.x

[45] Blanchard, J.H., Dunlap, D.A. and Fitchett, G. (2012) Screening for Spiritual Distress in the Oncology Inpatient: A Quality Improvement Pilot Project between Nurses and Chaplains. Journal of Nursing Management, 20, 1076-1084. http://dx.doi.org/10.1111/jonm.12035

[46] Caldeira, S., Carvalho, E.C. and Vieira, M. (2013) Spiritual Distress-Proposing a New Definition and Defining Characteristics. International Journal of Nursing Knowledge, 24, 7784. http://dx.doi.org/10.1111/j.2047-3095.2013.01234.x

[47] Herdman, T.H. and Kamitsuru, S. (Eds.) (2014) NANDA International Nursing Diagnoses: Definitions \& Classification, 2015-2017. Wiley Blackwell, Oxford.

[48] McSherry, W. and Jamieson, S. (2013) The Qualitative Findings from an Online Survey Investigating Nurses' Perceptions of Spirituality and Spiritual Care. Journal of Clinical Nurs- 
ing, 22, 3170-3182. http://dx.doi.org/10.1111/jocn.12411

[49] Brunjes, G.B. (2010) Spiritual Pain and Suffering. Asian Pacific Journal of Cancer Prevention, 11, 31-36.

[50] Emanuel, R., Scandrett, K.G. and Emanuel, L. (2012) The Cinderella of Medical Disciplines. Journal of Clinical Oncology, 30, 1387-1389. http://dx.doi.org/10.1200/JCO.2011.40.4764

[51] Tanyi, R.A. (2002) Towards Clarification of the Meaning of Spirituality. Journal of Advanced Nursing, 39, 500-509. http://dx.doi.org/10.1046/j.1365-2648.2002.02315.x

[52] McSherry, W. (2006) The Principal Components Model: A Model for Advancing Spirituality and Spiritual Care within Nursing and Health Care Practice. Journal of Clinical Nursing, 15, 905-917. http://dx.doi.org/10.1111/j.1365-2702.2006.01648.x

[53] Ferrell, B., Otis-Green, S. and Garcia, A. (2013) Nurses' Responses to Requests for Forgiveness at the End of Life. Journal of Pain and Symptom Management, 47, 631-641. http://dx.doi.org/10.1016/j.jpainsymman.2013.05.009

[54] Dunn, G. (2001) Patient Assessment in Palliative Care: How to See the "Big Picture" and What to Do When "There Is No More We Can Do". Journal of the American College of Surgeons, 193, 565-573. http://dx.doi.org/10.1016/S1072-7515(01)01076-6

[55] Fisher, J. (2011) The Four Domains Model: Connecting Spirituality, Health and Well-Being. Religions, 2, 17-28. http://dx.doi.org/10.3390/rel2010017

[56] Fitchett, G. (2002) Assessing Spiritual Needs: A Guide for Caregivers. 2nd Edition, Academic Renewal Press, Lima.

[57] McSherry, E., Kratz, D. and Nelson, W.A. (1986) Pastoral Care Departments: More Necessary in the DRG Era? Health Care Management Review, 11, 47-59. http://dx.doi.org/10.1097/00004010-198611010-00008

[58] Hungelmann, J., Kenkel-Rossi, E., Klassen, L. and Stollenwerk, R. (1996) Focus on Spiritual Well-Being: Harmonious Interconnectedness of Mind-Body-Spirit-Use of the JAREL Spiritual Well-Being Scale. Geriatric Nursing, 17, 262-266. http://dx.doi.org/10.1016/S0197-4572(96)80238-2

[59] Anandarajah, G. and Hight, E. (2001) Spirituality and Medical Practice: Using the HOPE Questions as a Practical Tool for Spiritual Assessment. American Family Physician, 63, 8189.

[60] Milligan, S. (2011) Addressing the Spiritual Care Needs of People Near the End of Life. Nursing Standard, 26, 47-56. http://dx.doi.org/10.7748/ns.26.4.47.s49

[61] Zikorus, P. (2007) The Importance of a Nurse's Presence: A Personal Story of Holistic Caring. Holistic Nursing Practice, 21, 208-210. http://dx.doi.org/10.1097/01.HNP.0000280933.65581.3b

[62] Hanson, L.C., Dobbs, D., Usher, B.M., Williams, S., Rawlings, J.M. and Daaleman, T.P. (2008) Providers and Types of Spiritual Care During Serious Illness. Journal of Palliative Medicine, 11, 907-914. http://dx.doi.org/10.1089/jpm.2008.0008 
Submit or recommend next manuscript to SCIRP and we will provide best service for you:

Accepting pre-submission inquiries through Email, Facebook, LinkedIn, Twitter, etc. A wide selection of journals (inclusive of 9 subjects, more than 200 journals)

Providing 24-hour high-quality service

User-friendly online submission system

Fair and swift peer-review system

Efficient typesetting and proofreading procedure

Display of the result of downloads and visits, as well as the number of cited articles

Maximum dissemination of your research work

Submit your manuscript at: http://papersubmission.scirp.org/

Or contact ojn@scirp.org 